Given that the liver receives blood draining into its sinusoids from the intestines and mesenteric fat, and that NKT cells patrol liver sinusoids, this discovery raises the intriguing possibility that immune-mediated mechanisms that suppress postprandial glucose production are inherently coupled to those that dampen hepatic immune responses to the gut-derived factors that have been implicated in inflammasome activation and deregulation of neurohumoral mechanisms that control feeding behavior and energy homeostasis. This insight, in turn, may have broad implications for the development of novel strategies to control obesity, insulin resistance, and T2DM.

Address correspondence to: Anna Mae Diehl, Division of Gastroenterology, Snyderman Building, Suite 1073, Duke University, Durham, North Carolina 27710, USA. Phone: 919.684.4173; Fax: 919.684.4183; E-mail: annamae.diehl@dm.duke.edu.

1. Meigs JB. Epidemiology of the insulin resistance syndrome. Curr Diab Rep. 2003;3(1):73-79.

2. Centers for Disease Control and Prevention. Diabetes Report Card 2012. Atlanta, Georgia, USA: Centers for Disease Control and Prevention, US Department of Health and Human Services; 2012.

3. Hotamisligil GS, Shargill NS, Spiegelman BM Adipose expression of tumor necrosis factor-alpha: direct role in obesity-linked insulin resistance. Science. 1993;259(5091):87-91.

4. Hotamisligil GS. Inflammation and metabolic disorders. Nature. 2006;444(7121):860-867.

5. Hotamisligil GS, Erbay E. 2008. Nutrient sensing and inflammation in metabolic diseases. Nat Rev Immunol. 2008;8(12):923-934.

6 . Stanya KJ, et al. Direct control of hepatic glucose production by interleukin-13 in mice. J Clin Invest. 2013;123(1):261-271

7. Roy B, Bhattacharjee A, Xu B, Ford D, Maizel $\mathrm{AL}$, Cathcart MK. IL-13 signal transduction in human monocytes: phosphorylation of receptor components, association with Jaks, and phosphorylation/activation of Stats. J Lenkoc Biol. 2003 ; 72(3):580-589.

8. Akaiwa $\mathrm{M}$, et al. Localization of human interleukin 13 receptor in non-haematopoietic cells. Cytokine. 2001;13(2):75-84

9. Surendar J, Mohan V, Rao MM, Babu S, Aravindhan V. Increased levels of both Th1 and Th2 cytokines in subjects with metabolic syndrome (CURES-103). Diabetes Technol Ther. 2001;13(4):477-482.

10. Sugimoto R, et al. 2005. Effect of IL-4 and IL-13 on collagen production in cultured LI90 human hepatic stellate cells. Liver Int. 2005;25(2):420-428.

11. Shimamura T, Fujisawa T, Husain SR, Kioi M, Nakajima A, Puri RK. 2008. Novel role of IL-13 in fibrosis induced by nonalcoholic steatohepatitis and its amelioration by IL-13R-directed cytotoxin in a rat model. J Immunol. 2008;181(7):4656-4665.

12. Weng HL, et al. 2009. The etiology of liver damage imparts cytokines transforming growth factor beta 1 or interleukin-13 as driving forces in fibrogenesis. Hepatology. 2009;50(1):230-243.

13. Gao B, Jeong WI, Tian Z. 2008. Liver: An organ with predominant innate immunity. Hepatology. 2008; 47(2):729-736.

14. Kotas ME, et al. Impact of CD1d deficiency on metabolism. PLoS One. 2012;6(9):e25478.

15. Szatmari I, et al. PPARgamma controls CD1d expression by turning on retinoic acid synthesis in developing human dendritic cells. J Exp Med. 2006; 203(10):2351-2362.

16. Ji Y, et al. Activation of natural killer T cells promotes M2 Macrophage polarization in adipose tissue and improves systemic glucose tolerance via interleukin-4 (IL-4)/STAT6 protein signaling axis in obesity. J Biol Chem. 2012;287(17):13561-13571.
17. Kremer M, et al. Kupffer cell and interleukin-12-dependent loss of natural killer T cells in hepatosteatosis. Hepatology. 2010;51(1):130-141.

18. Guebre-Xabier M, Yang S, Lin HZ, Schwenk R, Krzych U, Diehl AM. Altered hepatic lymphocyte subpopulations in obesity-related murine fatty livers: potential mechanism for sensitization to liver damage. Hepatology. 2000;31(3):633-640.

19. Li Z, Soloski MJ, Diehl AM. Dietary factors alter hepatic innate immune system in mice with nonalcoholic fatty liver disease. Hepatology. 2005; 42(4):880-885.

20. Yang L, Jhaveri R, Huang J, Qi Y, Diehl AM. Endoplasmic reticulum stress, hepatocyte CD1d and NKT cell abnormalities in murine fatty livers. $L a b$ Invest. 2007;87(9):927-937.

21. Miyazaki Y, et al. Effect of high fat diet on NKT cell function and NKT cell-mediated regulation of Th1 responses. Scand J Immunol. 2008;67(3):230-237.

22. Mantell BS, Stefanovic-Racic M, Yang X, Dedousis N, Sipula IJ, O’Doherty RM. Mice lacking NKT cells but with a complete complement of CD8+ T-cells are not protected against the metabolic abnormalities of diet-induced obesity. PLoS One. 2011; 6(6):e19831.

23. Lynch L, et al. Adipose tissue invariant NKT cells protect against diet-induced obesity and metabolic disorder through regulatory cytokine production. Immunity. 2012;37(3):574-587.

24. Margalit M, et al. Glucocerebroside ameliorates the metabolic syndrome in $\mathrm{OB} / \mathrm{OB}$ mice. J Pharmacol Exp Ther. 2006;319(1):105-110.

25. Elinav E, et al. Adoptive transfer of regulatory NKT lymphocytes ameliorates non-alcoholic steatohepatitis and glucose intolerance in ob/ob mice and is associated with intrahepatic CD8 trapping. J Pathol. 2006;209(1):121-128

26. Syn WK, et al. Accumulation of natural killer T cells in progressive nonalcoholic fatty liver disease. Hepatology. 2010;51(6):1998-2007.

27. Syn WK, et al. NKT cells stimulate hedgehog and osteopontin production to drive fibrogenesis in nonalcoholic fatty liver disease. Gut. 2012; 61(9):1323-1329.

\title{
A heartfelt response: new thyroid hormone- sensitive neurons in the hypothalamus
}

\author{
Douglas Forrest ${ }^{1}$ and Jürgen Wess ${ }^{2}$
}

${ }^{1}$ Nuclear Receptor Biology Section, Laboratory of Endocrinology and Receptor Biology, and 2Molecular Signaling Section, Laboratory of Bioorganic Chemistry, National Institute of Diabetes and Digestive and Kidney Diseases (NIDDK), Bethesda, Maryland, USA.

\begin{abstract}
Thyroid hormone is a well-known regulator of metabolic and cardiovascular functions, and signaling through thyroid receptors has differential effects on cells depending on the receptor isoform that they express. In this issue of the JCI, Mittag et al. provide evidence that thyroid hormone receptors are essential for the formation of a population of parvalbuminergic neurons in the anterior hypothalamus, linking, for the first time, impaired thyroid hormone signaling during development to cellular deficits in the hypothalamus. Since this newly discovered cell group is predicted to play a role in regulating cardiovascular function, these findings suggest that developmental hypothyroidism may be the cause of cardiovascular disorders later in life.
\end{abstract}

Conflict of interest: The authors have declared that no conflict of interest exists.

Citation for this article: J Clin Invest. 2013;

123(1):117-120. doi:10.1172/JCI67448.
Thyroid hormone plays a key role in regulating many developmental, metabolic, and cardiovascular processes $(1,2)$. Congenital hypothyroidism, which occurs in 1 in less than 3,000 births (3), and other thyroid gland disorders are associated with defects in the maturation and function of many tissues and organ systems. It has been a long-standing challenge to decipher the mechanisms by which thyroid hormone regulates such a wide range of cellular processes in so many different tissues. How does the same hormone stimulate the differentiation of an embryonic neuroblast but trigger an entirely different response in an adult liver cell? Thyroid hormone acts through the intracellular thyroid hormone receptor (TR), which belongs to the nuclear receptor family and acts as a ligand-regu- 


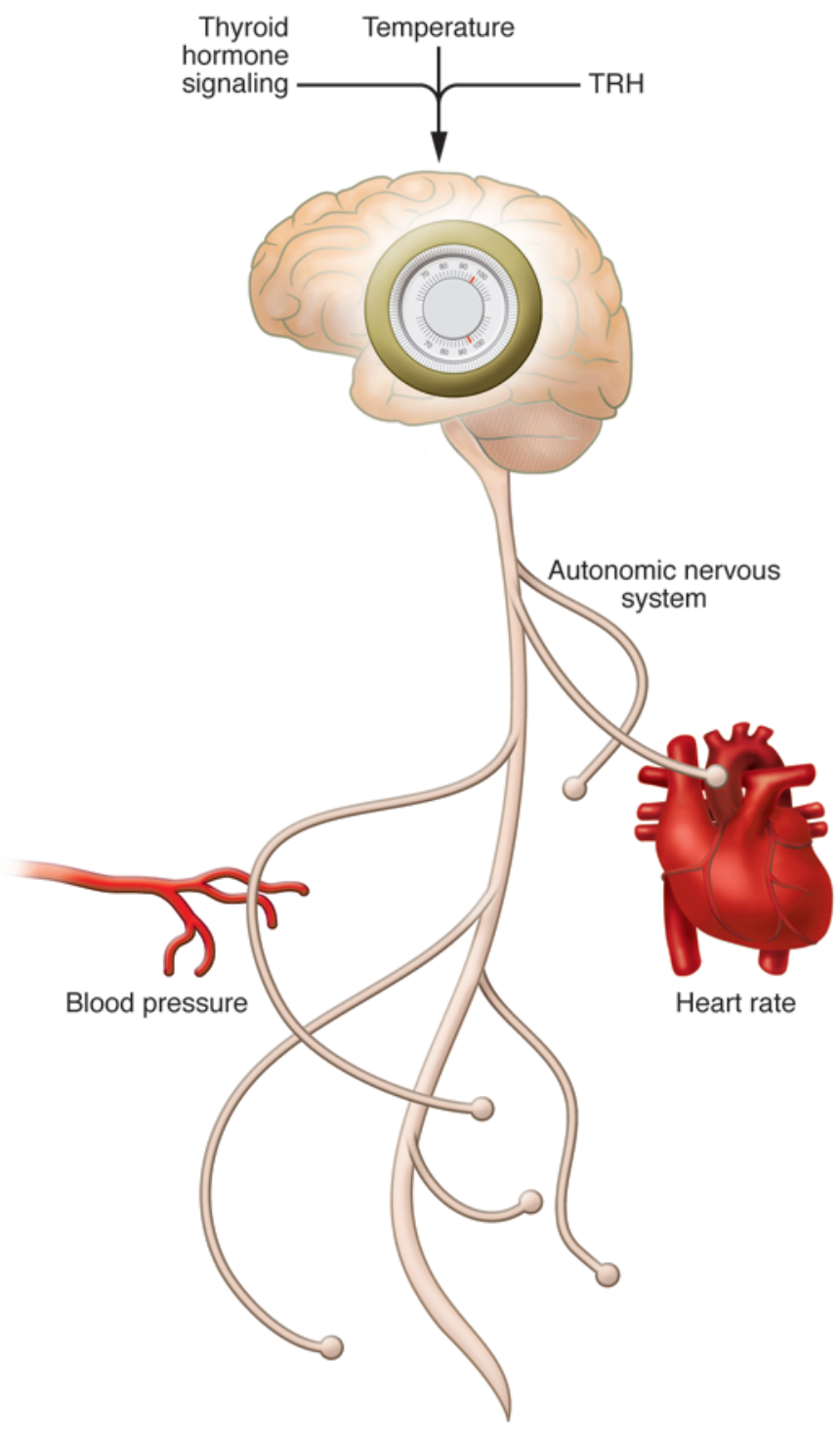

lated transcription factor $(4,5)$, eliciting cellular responses by binding to and regulating the expression of target genes. The binding of triiodothyronine (T3), the biologically active form of thyroid hormone, induces a conformational change in the TR that leads to a dynamic exchange of associated transcriptional corepressor and coactivator complexes.

T3 acts through three TR isoforms in humans and mice: TR $\alpha 1$, which is encoded by the THRA gene, and TR $\beta 1$ and TR $\beta 2$, which are encoded by the THRB gene. The differential expression of these receptor isoforms determines certain specific cellular functions; for example, TR $\beta 2$ in cone photoreceptors is required for color vision (6) and TR 1 in pyramidal neurons in the hippocampus may influence learning and memory (7). Mutations in the human THRA and THRB genes have been associated with a distinct spectrum of symptoms, consistent with the proposal that TR $\alpha 1$ and TR $\beta$ isoforms mediate specific functions. THRA mutations result in hypothyroid-like defects, with mental and physical retardation but with only marginal abnormalities in serum thyroid hormone levels $(8,9)$. In contrast, THRB mutations result in hyperactivity of the hypothalamic-pituitary-thyroid axis, with elevated levels of thyroid hormones and nonsuppressed thyrotropin as well as a variety of growth and neurological abnormalities (10). Relevant to the study in this issue of the JCI by Mittag et al. (11), TR $\alpha 1$ is expressed widely in the brain, including in the hypothalamus in rodents (12), which is the control center of central autonomic outflow (Figure 1).

\section{Figure 1}

The $\mathrm{pv}^{+}$neurons in the AHA are proposed to act as central integrators (indicated by the dial in the brain) that determine the set point for cardiovascular function. These neurons depend on thyroid hormone signaling for proper development and integrate temperature information to regulate cardiovascular parameters via modulating central autonomic outflow. Moreover, the activity of $\mathrm{pv}^{+}$neurons is regulated by $\mathrm{TRH}$. The downstream relay stations that transmit signals from the $\mathrm{AHA} \mathrm{pv} v^{+}$neurons to the heart remain unknown at present.

\section{Impaired thyroid hormone signaling causes specific defects in the hypothalamus}

Until recently, the cardiovascular and metabolic effects of thyroid hormone were thought to be mediated predominantly by TR isoforms expressed by peripheral tissues, including heart, skeletal muscle, or fat $(1,2)$. However, recent studies suggest that thyroid hormone can also modulate developmental, metabolic, and cardiovascular processes by acting on specific targets in the brain (13-15). The neuronal subpopulations and pathways involved in these CNS-dependent thyroid hormone effects remain poorly defined, particularly as far as the central cardiovascular actions are concerned.

Interestingly, Bochukova et al. (8) recently described a patient who was heterozygous for a THRA allele that expressed a dominant- 
negative TR $\alpha 1$ with the ability to inhibit wild-type TR function, causing resistance to thyroid hormone in various target tissues. In addition to other clinical impairments, this patient displayed bradycardia and low blood pressure, a phenotype resembling that observed in mouse models with similar dominant mutations, including the TR $\alpha 1$ R384C mutant studied by Mittag et al. (11, 15-17). These findings led to the speculation that thyroid hormone-dependent modulation of cardiovascular function may involve central target tissues that are critical for regulating proper autonomic (sympathetic and parasympathetic) outflow (15).

To gain insight into the neuroanatomical basis of these central actions of thyroid hormone, Mittag et al. initially studied TR $\alpha 1$ R384C mutant mice (11). These mice are heterozygous for the R384C point mutation that reduces T3-binding affinity of TR $\alpha 1$ by approximately 10 fold. Mittag et al. previously suggested (15) that central autonomic control of cardiovascular responses to stress, activity, or changes in environmental temperature was dysregulated in this mouse model. In the study by Mittag et al., the authors made the interesting observation that the level of parvalbumin (pv) mRNA was reduced by approximately 50\% in the hypothalami of TR $\alpha 1$ R384C mice (11). Of note, $\mathrm{pv}^{+}$cells are present not only in the hypothalamus but also in many other areas of the brain (18). Immunohistochemistry identified a small population of hypothalamic $\mathrm{pv}^{+}$cells localized in the anterior hypothalamic area (AHA) that had not been described previously. Importantly, in TR $\alpha 1$ R384C mice, this population of hypothalamic $\mathrm{pv}^{+}$cells was drastically reduced (by $\sim 70 \%$ ), as compared with that in wild-type control mice, while other hypothalamic $\mathrm{pv}^{+}$cell groups were unchanged. In addition, Mittag et al. found that the selective reduction in the number of $\mathrm{AHA} \mathrm{pv}^{+}$cells was due to a developmental defect caused by impaired signaling through both the $\alpha 1$ and $\beta$ TR isoforms (11).

To study the possible functional roles of the AHA $\mathrm{pv}^{+}$neurons, Mittag et al. carried out whole-cell patch-clamp recordings, using hypothalamic slices prepared from adult mice expressing GFP in $\mathrm{pv}^{+}$neurons. Interestingly, all analyzed $\mathrm{AHA} \mathrm{pv}^{+}$cells were responsive to changes in temperature ranging from $25^{\circ} \mathrm{C}$ to $40^{\circ} \mathrm{C}$, causing either excitation or inhibition in approximately $70 \%$ and $30 \%$ of the neurons, respectively. Additional studies suggested the involvement of specific ion channels in mediating these opposing electrophysiological effects. In a similar fashion, treatment with thyrotropin-releasing hormone (TRH) also led to either excitation or inhibition of $\mathrm{AHA} \mathrm{pv}^{+}$neurons. However, since no correlation was observed between the nature of the TRH response and the type of temperature sensitivity, the authors postulated the existence of at least four different subpopulations of AHA pv ${ }^{+}$neurons (11). Future studies aimed at better understanding the properties and potential physiological roles of these various $\mathrm{AHA} \mathrm{pv}^{+}$cell populations should be of significant interest.

\section{Potential physiological roles of AHA pv ${ }^{+}$neurons}

To explore the potential physiological relevance of the newly discovered $\mathrm{AHA} \mathrm{pv}^{+}$neurons, the authors selectively ablated approximately $40 \%$ of the $\mathrm{AHA} \mathrm{pv}^{+}$cells in wild-type mice. While the loss of this cell population did not induce major metabolic or behavioral phenotypes, it did lead to pronounced increases in systolic and diastolic blood pressure. Since the serum levels of hormones that are critically involved in blood pressure regulation remained unchanged in these mice, the authors proposed that the observed changes in cardiovascular function might be caused by altered autonomic outflow.

Moreover, following cold exposure $\left(4^{\circ} \mathrm{C}\right)$, AHA $\mathrm{pv}^{+}$-ablated mice displayed a pronounced increase in heart rate, as compared with that of control mice. This effect was not observed at thermoneutrality $\left(30^{\circ} \mathrm{C}\right)$. Mittag et al. also treated $\mathrm{AHA} \mathrm{pv}^{+}$-ablated mice with $\mathrm{N}$-methylscopolamine, a muscarinic receptor antagonist that interferes with the inhibitory cardiac parasympathetic actions of acetylcholine, and timolol, a $\beta$-adrenergic receptor antagonist that blocks the stimulatory sympathetic cardiac effects of norepinephrine (or epinephrine). They showed that the ability of the two antagonists to trigger changes in heart rate was significantly reduced in AHA $\mathrm{pv}^{+}$-ablated mice. Taken together, these findings strongly support the concept that AHA $\mathrm{pv}^{+}$neurons play a critical role in the central regulation of cardiovascular function.

\section{Future directions}

The study by Mittag et al. has important implications regarding the origin of cellular defects that lead to cardiovascular damage in hypothyroidism. Previous evidence indicated that the heart responds directly to T3 (1). Indeed, cardiomyocytes isolated from TR $\alpha 1$-deficient mice display abnormal inactivation kinetics of voltagedependent potassium currents (19). Thus, a key issue still to be addressed is the relative contribution of central hypothalamic circuits compared with that of peripheral heart responses in regulating overall cardiac function. Obviously, this question is relevant for understanding the bradycardia and low blood pressure phenotypes observed in a human patient carrying the THRA mutation (8) and in TR 1 R384C mice.

Fascinating questions remain to be addressed concerning the mechanism by which thyroid hormone regulates the development of the AHA $\mathrm{pv}^{+}$neurons. It is unknown whether there is a failure to generate these neurons or whether these neurons are initially formed but then succumb to cell death at a later stage. The answer to this question may have implications for our understanding of the pathophysiology of human congenital hypothyroidism. The study by Mittag et al., showing the involvement of TRs in the development of a new subgroup of hypothalamic neurons, complements other recent investigations of the genetic pathways that generate neuronal diversity in several hypothalamic nuclei (20).

Other key unanswered questions that arise from this work (11) concern the neuroanatomical basis for the distinct responses of the postulated four subpopulations of AHA $\mathrm{pv}^{+}$neurons and the nature of the connections through which these neurons regulate cardiac function.

In summary, the authors have expanded our perspective on the role of the hypothalamus in the central control of homeostatic functions. In addition, the findings alert us to the likelihood that thyroid hormone, sometimes considered to be an "old" hormone, will yet be found to mediate new functions. Contemporary techniques provide unprecedented opportunities for dissecting the roles of specific genes in defined cell populations. We may anticipate that continued exploration will identify additional developmental and physiological functions that are under the control of thyroid hormone signaling.

\section{Acknowledgments}

Both authors are funded by the Intramural Research Program of the NIDDK, NIH.

Address correspondence to: Jürgen Wess, Laboratory of Bioorganic Chemistry, Molecular Signaling Section, NIDDK, National Institutes of Health, Bldg. 8A, Room B1A-05, 8 Center Drive, Bethesda, Maryland 20892, USA. Phone: 301.402.3589; Fax: 301.480.3447; E-mail: jwess@helix.nih.gov. 
1. Kahaly GJ, Dillmann WH. Thyroid hormone action in the heart. Endocr Rev. 2005;26(5):704-728.

2. Silva JE. Thermogenic mechanisms and their hormonal regulation. Physiol Rev. 2006;86(2):435-464

3. Harris KB, Pass KA. Increase in congenital hypothyroidism in New York State and in the United States. Mol Genet Metab. 2007;91(3):268-277.

4. Sap J, et al. The c-erbA protein is a high affinity receptor for thyroid hormone. Nature. 1986; 324(6098):635-640.

5. Weinberger C, Thompson CC, Ong ES, Lebo R, Gruol DJ, Evans RM. The c-erb-A gene encodes a thyroid hormone receptor. Nature. 1986;324(6098):641-646.

6. $\mathrm{Ng} \mathrm{L}$, et al. A thyroid hormone receptor that is required for the development of green cone photoreceptors. Nat Genet. 2001;27(1):94-98.

7. Guadaño-Ferraz A, et al. Lack of thyroid hormone receptor alpha1 is associated with selective alterations in behavior and hippocampal circuits. $\mathrm{Mol}$ Psychiatry. 2003;8(1):30-38.

8. Bochukova E, et al. A mutation in the thyroid hormone receptor alpha gene. N Engl J Med. 2012; 366(3):243-249.
9. van Mullem A, et al. Clinical phenotype and mutant TRalpha1. NEnglJ Med. 2012;366(15):1451-1453.

10. Refetoff S, Weiss RE, Usala SJ. The syndromes of resistance to thyroid hormone. Endocr Rev. 1993; 14(3):348-399.

11. Mittag J, et al. Thyroid hormone is required for hypothalamic neurons regulating cardiovascular functions. J Clin Invest. 2013;123(1):509-516.

12. Bradley DJ, Towle HC, Young WS 3rd. Spatial and temporal expression of alpha- and beta-thyroid hormone receptor mRNAs, including the beta 2 -subtype, in the developing mammalian nervous system. J Neurosci. 1992;12(6):2288-2302.

13. Fliers E, Klieverik LP, Kalsbeek A. Novel neural pathways for metabolic effects of thyroid hormone. Trends Endocrinol Metab. 2010;21(4):230-236.

14. Lopez M, et al. Hypothalamic AMPK and fatty acid metabolism mediate thyroid regulation of energy balance. Nat Med. 2010;16(9):1001-1008.

15. Mittag J, Davis B, Vujovic M, Arner A, Vennstrom $B$. Adaptations of the autonomous nervous system controlling heart rate are impaired by a mutant thyroid hormone receptor-alpha1. Endocrinology.
2010;151(5):2388-2395

16. Kaneshige $M$, et al. A targeted dominant negative mutation of the thyroid hormone $\alpha 1$ receptor causes increased mortality, infertility, and dwarfism in mice. Proc Natl Acad Sci U S A. 2001; 98(26):15095-15100.

17. Liu YY, Schultz JJ, Brent GA. A thyroid hormone receptor $\alpha$ gene mutation $(\mathrm{P} 398 \mathrm{H})$ is associated with visceral adiposity and impaired catecholaminestimulated lipolysis in mice. J Biol Chem. 2003; 278(40):38913-38920.

18. Meyer AH, Katona I, Blatow M, Rozov A, Monyer $H$. In vivo labeling of parvalbumin-positive interneurons and analysis of electrical coupling in identified neurons. J Neurosci. 2002;22(16):7055-7064.

19. Johansson C, Koopmann R, Vennström B, Benndorf K. Accelerated inactivation of voltage-dependent $\mathrm{K}+$ outward current in cardiomyocytes from thyroid hormone receptor alpha1-deficient mice. J Cardiovasc Electrophysiol. 2002;13(1):44-50.

20. Shimogori T, et al. A genomic atlas of mouse hypothalamic development. Nat Neurosci. 2010; 13(6):767-775. 